\title{
Imágenes de la tiranía y tiranía de las imágenes en algunas comedias de Tirso de Molina

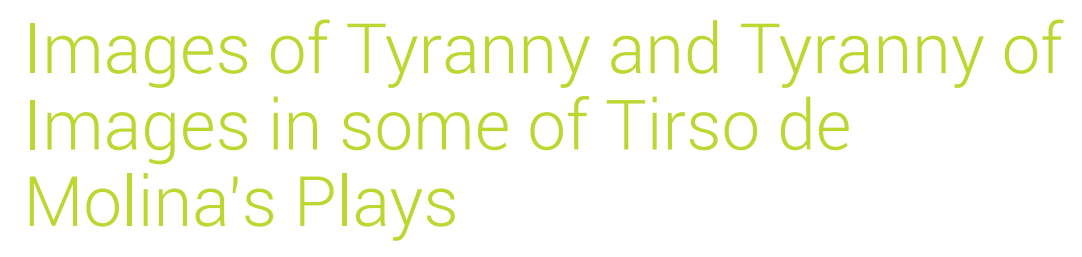

\section{Naima Lamari}

Université d'Avignon

EA 4277-ICTT

FRANCIA

naima.lamari@univ.avignon.fr

[Hipogrifo, (issn: 2328-1308), 7.1, 2019, pp. 457-468]

Recibido: 24-09-2018 / Aceptado: 08-11-2018

DOl: http://dx.doi.org/10.13035/H.2019.07.01.35

Resumen. Florecen en el Siglo de Oro los manuales de pedagogía y de educación de príncipes que teorizan sobre los principios de buen gobierno que han de regir al gobernante perfecto. No nos extraña por tanto que el teatro tirsiano suba a las tablas múltiples reflexiones acerca de los malos ejercicios del poder y del ars gubernandi a través de variadas y diversas formas de tiranía: desde la doméstica, en el ámbito individual y privado, con figuras despóticas de patres familiarum que obligan a sus hijos a un matrimonio de conveniencia como en Ventura te dé Dios hijo, hasta la dimensión colectiva y pública a través de malos gobernantes que contaminan su república con sus desenfrenadas pasiones como en La república al revés, pasando por la soldadesca que abusa de los villanos en Todo es dar en una cosa.

Siendo el teatro un género marcadamente visual con un gran poder persuasivo, Tirso recurre con frecuencia a modelos iconográficos, emblemáticos y simbólicos, a la hora de imaginar acciones o situaciones dramáticas, con el propósito de «enseñar, mover, hablar, y deleitar siempre y con todos géneros de gente». Mediante la representación alegórica, se sugiere al público todo un sistema de símbolos cuyo significado es convenientemente explicado por el texto. Tal íntima relación dialéctica que va en varios sentidos, de un arte a otro, vertebra dramas como La mujer que manda en casa, La vida y muerte de Herodes, La república al revés, La venganza de 
Tamar, que se pueden leer, ver y apreciar desde una clave simbólica. En este ensayo, pretendo demostrar cómo consigue Tirso, mediante el simbolismo del bestiario bíblico-medieval y las estrategias escénicas construir y deconstruir a la figura del tirano, creando al mismo tiempo una verdadera tiranía de la imagen.

Palabras clave. Tiranía; imágenes; teatro; Tirso.

Abstract. The Spanish Golden Age was a period when a great number of treatises dealing with the education of princes were written. These treatises established the principles of good government to be followed the perfect ruler. Therefore, it is not surprising that Tirso de Molina's drama contains numerous reflections on the misuse of power and on ars gubernandi. It is also possible to see numerous forms of tyranny, including domestic and personal despotism of fathers who force their sons to a marriage of convenience (Ventura te dé Dios hijo), public tyranny, in which bad rulers harm the Republic with their vices (La república al revés), and the military tyranny, in which the soldiers abuse the peasants (Todo es dar en una cosa). Since theater is notoriously visual, with great potential for persuasion, Tirso frequently uses iconographic, emblematic and symbolic models with the purpose of «teaching, moving, speaking to and entertaining all kinds of people». Thanks to the allegorical representation, the audience receives an array of symbols, whose meaning is conveniently explained by the text. This deep dialectic relationship configures plays like La mujer que manda en casa, La vida y muerte de Herodes, La república al revés, La venganza de Tamar, which can be read, seen and appreciated from a symbolic point of view. In this essay I intend to show how Tirso constructs and deconstructs the figure of the tyrant by using the symbolism of the biblical and medieval bestiary, and by creating a true tyranny of the image.

Keywords. Tyranny; Images; Comedias; Tirso.

Florecen en el Siglo de Oro los manuales de pedagogía y de educación de príncipes que teorizan sobre los principios de buen gobierno que han de regir al gobernante perfecto. No nos extraña por tanto que el teatro tirsiano suba a las tablas múltiples reflexiones acerca de los malos ejercicios del poder y del ars gubernandi a través de variadas y diversas formas de tiranía: desde la doméstica, en el ámbito individual y privado, con figuras despóticas de patres familiarum que obligan a sus hijos a un matrimonio de conveniencia como en Ventura te dé Dios hijo, hasta la dimensión colectiva y pública a través de malos gobernantes que contaminan su república con sus desenfrenadas pasiones como en La república al revés, pasando por la soldadesca que abusa de los villanos en Todo es dar en una cosa.

Según Mircea Eliade, dedicarse a la dimensión simbólica, supone que nos centremos en la filosofía, la historia, la religión, la sicología y el arte ${ }^{1}$. Ahora bien, en la España del Siglo de Oro, imágenes y palabras constituían eficaces instrumentos de propaganda para difundir y afianzar la tradición cristiana. Siendo el teatro un género marcadamente visual con un gran poder persuasivo, Tirso recurre con

1. Eliade, 1963. 
frecuencia a modelos iconográficos, emblemáticos y simbólicos, a la hora de imaginar acciones o situaciones dramáticas, con el propósito de «enseñar, mover, hablar, y deleitar siempre y con todos géneros de gente»². Mediante la representación alegórica, se sugiere al público todo un sistema de símbolos cuyo significado es convenientemente explicado por el texto. Tal íntima relación dialéctica que va en varios sentidos, de un arte a otro, vertebra dramas como La mujer que manda en casa (MM), La vida y muerte de Herodes (VM), La república al revés (RR) o La venganza de Tamar (VT), que se pueden leer, ver y apreciar desde una clave simbólica.

En este ensayo, pretendo demostrar cómo consigue Tirso, mediante el simbolismo del bestiario bíblico-medieval y las estrategias escénicas construir y deconstruir a la figura del tirano, creando al mismo tiempo una verdadera tiranía de la imagen.

\section{UN BESTIARIO AL SERVICIO DE LA TIRANÍA PASIONAL}

En el corpus que he seleccionado como objeto de mi estudio, se documentan numerosos casos de referencias al mundo zoológico, con su densa carga connotativa, bestiario bíblico y a veces fabuloso que el espectador atento debía de ser capaz de descifrar, al recordar el valor emblemático que encierra. Amén de unir armoniosamente la imagen visual con la imagen escritural, estas ocurrencias animales, todas de axiología negativa y de índole ejemplar, se hallan estrechamente vinculadas con una situación, un ambiente y sobre todo con un personaje: el de Jezabel en $M M$, Herodes en VM y Constantino en RR. Aparecen simbólicamente en escenas estratégicas de las obras para presagiar funestos acontecimientos, funcionando así a modo de signos de mal agüero, a la vez que propician el arranque literario y enhebran la trama novelesca.

Dentro del marco de los dramas de conquista del poder y de sus abusos, el animal de mayor transcendencia política y moral lo constituye el caballo, por ser este un catalizador de sentidos simbólicos y literales que viene a definir al tirano ${ }^{3}$. Digna de ponderación es la acotación descriptiva, de fuerte condensación icónica, que abre la MM (p. 383): Música de todos géneros y por una parte suben al tablado, habiendo venido a caballo al son de un clarín, en hábito de caza, Jezabel, Raquel, Criselia, y cazadores, con perros, ballestas y venablos. Por la otra parte al mismo tiempo suben también, al son de cajas y trompetas, soldados marchando, y entre ellos Nabot, Abdías y Jehú; detrás de todos, a lo hebreo con corona y bastón, el rey Acab. Tocan chirimías y en estando todos arriba llega Acab a Jezabel y dice.

Como puede apreciarse, el primer elemento decisivo en la dramatización y construcción de la figura de Jezabel en tanto que tirano es precisamente el caballo que funciona aquí a modo de prolepsis, al anticipar el final trágico de la comedia, siendo este un presagio de muerte y de destrucción. Si es verdad que participa del engrandecimiento y de la superioridad ostentosa de esta, que en posición elevada, ejerce un poder despótico sobre sus súbditos, simboliza también la hambruna ve-

3. No solo simboliza el caballo el poder del tirano. Ver Arellano, 2000, p. 240 y Oteiza, 2017. 
nidera, recordando así al jinete del Apocalipsis: «Ni el ganado ha de hallar pastos, / ni los hombres qué comer, / porque vuestras rebeldías / se castiguen de una vez» (vv. 871-874). Esta alusión a la sequía y a la privación de bienes materiales encaja perfectamente en la red de correspondencias que pretende trazar Tirso entre los pecados nacidos de la tiranía y el castigo final del gobernante impío. El motivo del banquete y/o de la hambruna cumple una función estructurante y metafórica en los dramas de tiranía: el hambre feroz es expiación que Dios envía por las impiedades de sus gobernantes. El pan supone comunión, dado que está destinado a repartirse, siendo la hospitalidad y la caridad deberes sagrados con que los impíos monarcas Jezabel, Acab y Herodes no cumplen. En VT, la riqueza alusiva al motivo del banquete da pie a la expresión de la tiranía carnal: Amón es un Adán que va a sucumbir a la tentación de la lujuria al comerse la fruta prohibida del árbol del huerto, siendo aquí la fruta la princesa Tamar, y el acto de devorar una metáfora de la posesión sexual que culminará en la escena del intercambio verbal, físico y visual entre los dos hermanos, en que le trae esta la comida, la cual cobra un valor altamente metafórico, por sus claras alusiones sexuales. El campo semántico de la comida («comer», «manjar», «alentando el apetito», vv. 985-987, «guisar», v. 1003) hace hincapié en la analogía que existe entre el acto de comer y el de copular, poniéndose así al servicio de la erotización de las imágenes. El mercedario transforma el motivo del hambre y/o de la comida en materia literaria para trasladarlos luego a su público contemporáneo desde una clave cristiana.

La metáfora cinegética, complementaria de la metáfora erótica, constituye el punto de arranque de la construcción de la figura de Jezabel, cuya actuación en el reino se fundamenta en el sexo y en el poder, dos instrumentos de los que se vale para legitimar la religión de Baal, una forma de culto basada en la lujuria y en la hipocresía, invirtiéndose así los códigos morales y los valores éticos áureos. En vista de lo expuesto, esta portentosa escena de exposición, acorde con las expectativas del público, adquiere pues una dimensión eminentemente simbólica, al presentar a una Jezabel de aspecto amazónico y viril a semejanza de una nueva Semíramis, aquella reina legendaria de Asiria que ejecutó a su marido Nino, usurpando así el trono de su hijo Ninias. No obstante, se opera una subversión de la leyenda, ya que en vez de convertirse en sustituta de Nino, Jezabel le propone a Nabot compartir el trono y actuar como privado 4 .

Lo mismo podría decirse de otro drama de la serie bíblica: VM en que recrea y dramatiza el Tirso historiador las circunstancias del amor tempestuoso y trágico de Herodes por su esposa Mariadnes, inscribiéndose dentro del tenso contexto de las luchas fratricidas entre Hircano II y su hermano Aristóbulo por la sucesión al trono. Ahora bien, este tipo de comedia es propicio para recurrir a diversas técnicas y modalidades de visualización pictórica y verbal, a veces con claras referencias emblemáticas, y a una serie de efectos admirables, con el propósito de producir en los espectadores, y en el desenlace, un efecto emocional apoteósico. Si en MM metaforiza el caballo la lujuria y la religión orgiástica de la reina impura, alcanza en VM un relieve extraordinario al convertir a la figura evangélica de Herodes en héroe

4. Ver Bravo Vega, 1998, p. 232. 
de las epopeyas griegas cuyo periplo épico-mítico, jalonado de peligros y de obstáculos, recuerda el de Ulises. Al reducir a cenizas la ciudad de Armenia, destruye en realidad Herodes otra Troya, asimilándose este al caballo destructor, al paladín que se ha introducido secretamente en la choza de Mariadnes con miras a engañarla. Pero es asimismo Pegaso, el fabuloso caballo con alas, o aún el caballo negro del mito platónico del carro alado que, «abrasado» por la llama de Venus, «corre» de Ascalón a Jerusalén para «fertilizar su sangre / en himeneo conforme» (p. 243), simbolizando así las pasiones del alma. Amén de encerrar una amplia gama de significados que revelan evidentes connotaciones eróticas, tal asociación del príncipe con el animal deja presagiar, no solo su caída simbólica, sino también la de la Infanta, que cae de su caballo a principios del acto segundo. La inclinación barroca por el aspecto visual descubre en la palabra el elevado poder de suscitar imágenes que conllevan claras alusiones de origen emblemático. La imagen del caballo desbocado, que se extiende ampliamente por los libros de emblemas morales (Covarrubias por ejemplo) y bestiarios ${ }^{5}$ aún por tratados de alegorías como los de Ripa, y que forma parte del repertorio visual común de la época, simboliza la ceguera pasional y la corrupción moral del disoluto monarca.

También, es la tiranía del deseo carnal, metaforizada de nuevo por el caballo desbocado, la que transforma a Constantino de $R R$ en «fiero matricida», según exclama la emperadora Irene, su madre: «Y pues prenderme ha mandado / cuando sus vicios refreno, / despedezar quiere el freno / para correr desbocado» (p. 191).

Sin embargo, más allá de su connotación erótica, el caballo adquiere un significado político, y sirve como ejemplo negativo al representar las fallas morales y la vileza del tirano cuyos actos y conducta contradicen los dictados del arte de gobernar del rey modelizado en la tradición cristiana. La dicotomía hombre/bestia, heredada de Maquiavelo, junto con la alegoría de la caza y la metáfora del cazador que, acompañado por su jauría de perros persigue a su presa, están al servico de la caracterización del tirano incapaz de anteponer su deber político a su pasión.

Movidos por intereses primarios sin atenerse a las leyes morales o religiosas, tanto Jezabel, como Herodes o aún Constantino, quedan reducidos a predadores insaciables tildados alternativamente de fieros, bárbaros, monstruos, locos, traidores, arrogantes... Dignos de interés son los ecos, correspondencias y simetrías entre $M M$ y $R R$ que clausuran con una portentosa escena de cacería destinada a atenazar el ánimo del espectador y envolverlo en unas imágenes que desprenden una tensión agotadora. Los ruidos de caja, de «voces que atruenan el viento», los ladridos de los perros, los movimientos hacia delante y hacia atrás del cazador en la espesura del bosque con zarzas, metaforización a su vez de la profundidad de los pecados del tirano Constantino y de su extravío, escenifican el drama de un combate final simbólico entre las fuerzas del mal -la tiranía- y las del bien -el restablecimiento del orden, ilustrando así el bivium que el hombre ha de escoger. La imagen de la persecución del jabalí, en $R R$, metáfora de la emperadora acosada, y el simbolismo canino en $M M$, remiten a la crueldad, a la impureza y a la perver-

5. Ver Arellano, 2011, p. 184. 
sidad de los fallidos monarcas, vicios estos que constituyen causas suficientes para quitarles el trono. Es más: la presencia de los perros, animales impuros, no solo adelantan el lastimoso final de Jezabel, arrojada a los perros, sino que ponen de relieve al mismo tiempo la circularidad de la obra y la imposibilidad de la pérfida reina de escapar de su destino. Jezabel queda dibujada como una mujer belicosa con sus atributos guerreros, a semejanza de Diana, la diosa cazadora y vengadora. La ironía radica en que es Jezabel la que caza su presa a principios de la primera jornada, y eso que, será ella la cazada a finales del drama. Lo mismo ocurre para Constantino que, de cazador sediento de capturar su presa, se convierte en el desenlace en objeto de la caza misma. La pastora Fenisa de VM recuerda además que la costumbre que tienen las damas de corte de salir de caza es obra del demonio.

Al simbolismo equino y canino, se suma el ornitológico con su fuerte poder de significación mediante múltiples referencias a las aves de rapiña, tales como el halcón, el cuervo y el águila que remiten al reino del mal, a las pasiones negativas, y a los bajos instintos. El halcón, ave de presa, de mal agüero, símbolo de guerra y de victoria militar pero también de concupiscencia y de libertad dañosa, que se posa sobre la mano de Jezabel, nada más salir a escena esta con el rey Acab, se puede leer ya como la traición de la pecadora que intentará engañar a su esposo seduciendo a Nabot ${ }^{6}$. El movimiento descendente del halcón sirve para que la caída de la reina y su castigo final sean aún más ejemplares en el público impresionable.

Otra ave relevante para caracterizar a la tiránica reina e insistir en su impiedad y en su ambigüedad, lo constituye el cuervo, primera ave que se nombra en la Biblia y que llevó milagrosamente comida a Elías durante una hambruna (1 R. 17:4, 6). (En cantando bajan dos cuervos por el aire y el uno arrebata un pan y el otro una ave asada y vuelven a volar, y levántanse). Merece atención especial esta acotación de gran carga simbólica: surgen los cuervos inesperada y bruscamente en una escena de amor cortés, de aparente serenidad e intimidad en que Jezabel y Acab, acompañados de músicos, comparten un momento privilegiado: el de la comida, en el lugar ameno e idílico que es el jardín. Lo milagroso consiste aquí en la interferencia y la simultaneidad entre la música profana de los cantantes y los graznidos amenazantes de los cuervos que no son sino mensajeros divinos con misión casi profética.

A continuación, Tirso trae a colación la canción «En la prisión de unos hierros», sacada del romance de Fonte frida del siglo XVI5, cuyos versos prolépticos y de malos presagios, aluden a la soberbia del águila, única ave capaz de mirar de hito en hito al sol, pero también a su aspecto demoníaco por nutrirse de la rapiña, con el propósito de ennegrecer a la figura de Jezabel. En $R R$, Lidora, esposa del tiránico Constantino se compara con una criatura bicéfala, por su fisionomía monstruosa: «dos caras suelen dar a la mujer, / una hermosa y otra fea». De guerrera tentadora pasa a ser Jezabel una ave monstruosa, una «harpía de Sidón» (v. 853), esto es, una usurpadora con la cara de una mujer y el cuerpo de una ave de rapiña 
asquerosa. Tirso juega con las diversas posibilidades expresivas del conceptismo y con la estrategia del símbolo, reforzando así el carácter bipolar y ambivalente de la figura del tirano.

No menos relevante es la imagen bíblica del lobo que devora al cordero convocada por Tirso en VM para llevar al extremo los vicios del rey judío hasta desnaturalizarle, vaciándole de toda esencia histórica y bíblica, y convertirle en un monstruo dotado de dos únicos órganos: las manos y los dientes, armas de destrucción y de despedazamiento. De añadidura, la sed de sangre constituye uno de los motivos más comunes en los dramas de tiranía: tanto VM como MM escenifican los actos sanguinarios del tirano «hidrópico de sangre»: si Herodes termina saciando su sed de sangre y expira, en un arranque extremado de ira, no menos espectacular será el castigo de Jezabel a la que los soldados y Coriolín echan abajo, derribándola de la torre y arrojándola a los perros. La fuerza metafórica del derramamiento de la sangre sacrificial, de ese líquido vital sagrado que solo pertenece a Dios transforma a Jezabel en un ser impuro, en una ogresa que viola la prohibición de la sangre como alimento, presentándose esta como una variante femenina del culpable de la degollación de los Santos Inocentes: «Yo le beberé la sangre. / Yo pisaré su cabeza. / ¡Loca estoy! No viva un hora / quien reinando no se venga» (vv. 1915-1918). La violenta expresividad de estos versos suenan como un eco a los de Herodes, el rey sanguinario, predador, e infanticida de VM, quien exclama: «Lobo soy, corderos busco, / vuestra sangre me sustente », siendo los corderos, las víctimas expiatorias por excelencia. Los dos animales más simbólicos de la cultura judeo-cristiana así como el valor sacrificial del discurso sirven perfectamente a los intereses del mercedario que pretende amplificar los motivos que sustentan la obra: la traición, la conspiración y la usurpación del poder, sumiéndonos así en un ambiente asfixiante de maquinaciones. El palacio real, espacio de la tiranía, evoluciona también en antro monstruoso, en lugar inhospitalario de ocultamiento, en que reinan un tenso silencio y una atmósfera de clandestinidad y de opresión. Con ser la corte un espacio abierto, se nos aparece paradójicamente como lugar de encierro, de enajenación, un sitio laberíntico del que nadie saldrá vivo.

A modo de conclusión parcial, puede afirmarse que la reelaboración simbólica y alegórica del mundo zoológico originado en la tradición bíblica, en los bestiarios medievales y en los libros de emblema, apuntan a deslegitimar simbólicamente a aquellos fatuos monarcas que carecen de la virtud de la templanza, y que no imitan la política de Dios y el gobierno de Cristo.

\section{LAS ESTRATEGIAS ESCÉNICAS}

El caso de los objetos escénicos a partir de los cuales construye Tirso un elaborado y complejo sistema de signos (semiótica textual y semiótica visual) merece una consideración minuciosa. Entre estos objetos escénicos empleados con fines de amplificación expresiva, destacan las insignias del poder temporal tales como la corona, la espada, el estoque, el mundo o aún el anillo, pero en vez de legitimar 
el poder de los monarcas, sublimándolos, sirven para advertirlos contra cualquier forma de desgobierno, funcionando así a modo de signos premonitorios.

En $R R$, la concepción visual y plástica de la segunda acotación escénica hace que el espectador centre sus cinco sentidos en las tablas, al construirse como un lienzo barroco cromático o tableau-vivant, que destaca no solo por su perfección compositiva, sino también por la concentración de atributos iconográficos que se revisten de significados simbólicos y enriquecen la composición, tales como la mesilla sobre la que están dispuestos objetos alusivos a la vida mundana (la fuente de plata) y otros al universo simbólico del poder (la corona, el estoque y el mundo): «Tocan música; descubren una cortina detrás de la cual estará, debajo de un dosel, Constantino, y a sus lados, y en pie, Leoncio, Andronio, Macrino, y otros. A un lado, en una mesilla, estará sobre una fuente de plata la corona, el estoque, y el mundo».

Este bodegón o tableau d'apparat desvela la falsedad del poder e invita al espectador a desengañarse de este mundo que debe ser visto con los ojos que la vanitas recomienda. Tal ceremoniosa y suntuosa escena de apertura, elaborada según un movimiento ascendente, y aparentemente destinada a magnificar al monarca, no funciona sino como un verdadero trompe l'oeil destinado a recordar al público joven de los corrales lo perecedero y lo ilusorio del poder. Lo que se cree y se ve real se torna falsedad y engaño, siendo la vida una representación que el rey ha de mirar para desenmascararla, por lo cual, la mirada debe invertirse para diferenciar las apariencias de la verdad. Una vez terminada la vida, el soberano se despojará, no solo de los atributos de sus poderes temporales, sino también del papel que representa para alcanzar el «eterno descanso de la gloria».

Constantino sale a escena debajo de un dosel, entoldadura que se suele utilizar en las procesiones para resguardar al monarca, confiriéndole así distinción y supremacía. Por la verticalidad de su techo y su forma geométrica, el dosel contribuye a sacralizar al rey que, situado en la cumbre de la pirámide, ha de mirar por el bien común, elevándose así hacia los cielos. Mas no ascenderá Constantino a los cielos sino que descenderá a los abismos de la tiranía como deja presagiar su caída corporal efectiva, y no metafórica, al bajar del «asiento falso». Primera advertencia de Dios y primera estrategia de inversión.

A la caída espectacular del rey, se suma otro signo de mal agüero que de nuevo funciona a modo de prolepsis: la rotura del estoque, metaforización del desviado ejercicio del poder del soberano que arruina su familia y su reino. El uso del pretérito indefinido, la isotopía del hundimiento y de la decadencia, así como la retahíla de formas verbales no personales suenan como un juicio irrevocable: «caí en tierra y la espada / se me quebró», (p. 384), sellando claramente la precipitada perdición de Constantino. La rotura de la espada, sinónima de división, adquiere pues una dimensión binaria, anticipando así la ruptura de la unidad del reino y profetizando al mismo tiempo el preludio de la discordia. La relación simbólicamente causal entre el rompimiento del estoque, símbolo por antonomasia de la potestas y de la suprema justicia, y la pérdida del trono real confiere a la obra una sólida coherencia interna y una fuerte unidad temática y estructural. En vista de lo expuesto, resulta significativa la dialéctica del ascenso y de la caída, que ejemplifica los efectos de 
los inevitables giros de la rueda de la Fortuna, al introducir una nueva clave interpretativa de comprensión estética y moral de la obra. Constantino sube e Irene baja, produciéndose así los dos movimientos verticales complementarios de la rueda de la Fortuna, representada en una apariencia de carácter emblemático ${ }^{7}$ como una diosa pagana ciega y mudable (p. 423). La trabada escenificación de la estrepitosa caída del joven monarca a principios de la comedia cobra un significado simbólico, haciéndose manifestación de la verdad divina, en otras palabras, revelación en el sentido cristiano de la palabra. La forma degenerada de gobierno del tirano Constantino ocasiona el desprecio del derecho de sus súbditos y sobre todo la virtud ajena que impide la conquista de sus bienes espirituales. Si la caída corporal del príncipe evidencia la pérdida de su trono, la caída del guante ilustra metafóricamente el desarme de Constantino ante la belleza de Lidora y su ocaso moral. Se encadenan inexorablemente los hechos: tras la rotura del estoque, el mundo se abre en cuatro partes que corresponden a los 4 puntos cardinales y al símbolo de la cruz que deja presagiar la victoria de la verdad sobre la ceguera de la tiranía.

En MM, los efectos nefastos de la tiranía quedan plasmados mediante otro objeto altamente simbólico: el del anillo que Acab le entrega a su esposa, cediéndole así todos los poderes. Tal gesto de alcance casi mágico recuerda el de Faraón, otro idólatra pagano evocado en la Biblia (Génesis, 41, 42), que se quitó el anillo, símbolo de autoridad, para darlo a José, al nombrarlo consejero. Con esta cesión del poder, Acab abdica y rompe la sacralidad de su compromiso, no solo de monarca sino también de marido, haciendo que Jezabel revista la máscara del poder absoluto, y se metamorfosee en monstruo bicéfalo, en ser maléfico, tentacular y sobre todo híbrido que atrapa y devora a sus víctimas. Lejos de ser un simple adorno, el anillo participa del enmascaramiento de Jezabel cuyos apetitos de avasallar a sus súbditos alcanzan su paroxismo, convirtiéndose así la maldita sortija en una sinécdoque de su ser.

Tanto MM como RR se articulan en torno a la imagen operativa del mundo que se muestra en su revés como el reflejo del espejo, símbolo por excelencia de la vanidad y de la voluptuosidad. Al igual que Narciso, se enamora Jezabel de su propia imagen al contemplarse, peinarse y tocarse en contadas ocasiones, y si el castigo del bello joven se debe a su comportamiento cruel con la ninfa Eco, el de Jezabel se justifica, no tanto por su lujuria, sino como por su tiranía y su ceguera diabólica. La vanidad de Jezabel resalta igualmente al pintarse esta y peinarse antes de ir al encuentro de Jehú con vistas a seducirlo y quedarse en el trono. Lo mismo ocurre en $R R$ en que Lidora sale a tocarse al espejo, pero a la inversa de Jezabel que ve en él los funestos acontecimientos venideros, esta no ve más que su propia imagen, la cual se proyecta después en los ojos de Constantino, constituyendo la mirada una prolongación del espejo que le revelará su infeliz suerte. Mediante el simbolismo de los ojos, se entremezclan los destinos de Constantino y de Lidora: «Pues, no sé cómo, que dejo / de mirarme en el espejo mi bien, por mirarme en ti» (p. 420).

Otros objetos simbólicos, alusivos a la vida material y mundana, tales como las joyas, el diadema, las perlas, el marfil del peine, el lujo de los tejidos, los botones

7. Sobre este particular ver Arellano, 2011 
de oro invitan al espectador a desengañarse de este mundo tocado de locura. Esta típica composición de vanitas o de psique, junto con la abigarrada paleta cromática desplegada al escoger Lidora el vestido (el color de ropa pajizo y encarnado, el morado, el turquesado, el verde oscuro), hacen hincapié en la fugacidad de la vida y la inutilidad de los placeres sensoriales ante la certeza de la muerte que agarrará a la aduladora Jezabel en un desenlace trágico y eminentemente teatral.

De la misma manera, la presencia del espejo no solo viene a enfatizar la ambivalencia de la reina y la duplicidad de Lidora, sino también su frivolidad, al reflejar este una imagen distorsionada, invertida, y por tanto, ilusoria de sí misma. La autocontemplación deriva aquí en la fascinación enfermiza por su propia imagen, según revelan estos versos de Lidora: «mírate tú en tu retrato / y verás cuán bien pareces». La metáfora barroca del espejo le posibilita al dramaturgo insistir en los yerros sinfín de la reina negra que nunca fue capaz de hacer prueba de clarividencia a la hora de descifrar la concatenación y precipitación de las maldiciones de Raquel y de las profecías de Elías. En este sentido, el espejo dista mucho de ser sinónimo de revelación, ya que no favorece aquí la contrición de Jezabel.

Si es verdad que desde la Antigüedad, el espejo es el objeto que le permite al hombre ver quién es, no es así para Jezabel que se hunde en la profundidad de sus pecados. Más allá de su función de objeto de embellecimiento, el espejo es el instrumento mágico que dice la verdad, el «instrumento de visión indirecta» ${ }^{8}$, al proyectar no solo imágenes que ocurrieron en el pasado, sino también imágenes que ocurrirán en el futuro, según revelan estos versos terroríficos de Jezabel:

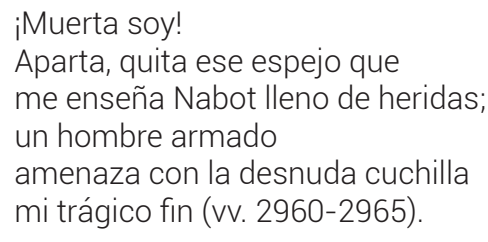

El poder de adivinación del instrumento especular lo volvemos a encontrar en $R R$ : al mirarse Constantino en él, ve su triste final: «un hombre armado / del propio rostro y figura / de Leoncio, que procura / matarme». Incapaz de descifrar este signo divino, el rey atribuye esta visión milagrosa a un encantamiento. Por la transparencia de su cristal, el espejo tan solo refleja lo que ve, sin las máscaras que el ser humano se pone, pero Constantino sigue en su extravío. Esta escena del tocador la inserta Tirso en realidad para escarmentar al público, siendo Dios el mejor espejo donde el gobernante, vicario de Dios en la tierra, ha de mirar. 
FINAL

En resumidas cuentas, podemos alegar, a la luz de estas aclaraciones, que el poeta Tirso va construyendo y deconstruyendo a la figura del tirano presuntuoso, vanidoso y sangriento, trayendo a colación cuantos recursos barrocos aterrorizan al espectador y apelan a su imaginación, tales como la visualización verbal, la eficacia narrativa, emblemática y alegórica de las imágenes, el juego especular de las miradas y el de la ilusión óptica, las sugerencias visuales y sensorialistas, las estrategias del símbolo (el bestiario bíblico, los objetos escénicos), en otras palabras, la teatralidad del arte, con el propósito, no solo de representar acciones, anticipando en forma pictórica lo que va a suceder en el escenario, sino también de deslegitimar el poder nocivo y opresivo del tirano usurpador e impío, legitimando así al mismo tiempo el poder de derecho divino del monarca.

Al llevar a las tablas modelos de conducta extremos, enfoca Tirso una cuestión que preocupaba a sus contemporáneos, las consecuencias desastrosas de los abusos del poder real y la corrupción de las formas del gobierno, a la vez que advierte al heterogéneo público sobre los males de la lujuria, de la soberbia y del paroxismo colérico, enalteciendo así el buen gobierno fundamentado en el bien común y en las virtudes regias de la prudencia y de la sabiduría. No quisiéramos terminar sin agregar que la figura del tirano es dramáticamente más atractiva que la del monarca deficiente.

\section{BIBLIOGRAFÍA}

Arellano, Ignacio, «Estrategias de inversión en La república al revés, comedia política y moral de Tirso de Molina», en Tirso de Molina: del Siglo de Oro al siglo XX, ed. Ignacio Arellano, Blanca Oteiza, María C. Pinillos y Miguel Zugasti, Madrid, Revista Estudios, 1995, pp. 9-26.

Arellano, Ignacio, «Visiones y símbolos emblemáticos en la poesía de Cervantes», Anales cervantinos, 34, 1998, pp. 169-212.

Arellano, Ignacio, «Elementos emblemáticos en las comedias religiosas de Calderón», en Calderón: una lectura desde el siglo XXI, coord. María Gómez y Patiño, Alicante, Instituto Alicantino de Cultura «Juan Gil Albert», 2000, pp. 219-247.

Arellano, Ignacio, Los rostros del poder en el Siglo de Oro: ingenio y espectáculo, Sevilla, Renacimiento, 2011.

Bravo Vega, Julián, «Los "dramas bíblicos" de Tirso y algunas de sus implicaciones ideológicas», en El escritor y la escena. Actas del VII Congreso de la Asociación Internacional de Teatro Español y Novohispano de los Siglos de Oro (1998, Ciudad Juárez), México, Universidad Autónoma de Ciudad Juárez, 1998, pp. 63-77.

Eliade, Mircea, Aspects du mythe, París, Gallimard, 1963. 
Jónsson, Eimar Már, Speculum. Recherches sur le symbolisme du miroir et la naissance d'un genre littéraire, thèse de doctorat de 3e cycle en Histoire, Université de Paris I, 1985.

Oteiza, Blanca, «El poder de la imagen en la calle y el teatro», Ínsula, 843, 2017, pp. 24-27.

Portús Pérez Javier, El arte de mirar. La pintura y su público en la España de Velázquez, Madrid, Istmo, 1997.

Tirso de Molina, La mujer que manda en casa, ed. Dawn Smith, en Obras completas. Cuarta parte de comedias I, Madrid, Revista Estudios/Publicaciones del Instituto de Estudios Tirsianos, 1999, pp. 359-486.

Tirso de Molina, La república al revés, en Obras dramáticas completas, ed. Blanca de los Ríos, Madrid, Aguilar, 1969, vol. I.

Tirso de Molina, La venganza de Tamar, en Obras dramáticas completas, ed. Blanca de los Ríos, Madrid, Aguilar, 1946, vol. I.

Tirso de Molina, La vida y muerte de Herodes, en Obras de Tirso de Molina, ed. Pilar Palomo, Madrid, Atlas (BAE, 238), 1970, vol. IV. 